\title{
Em busca dos rastros perdidos da memória ancestral: um estudo de Um defeito de cor, de Ana Maria Gonçalves
} Zilá Bernd $^{1}$

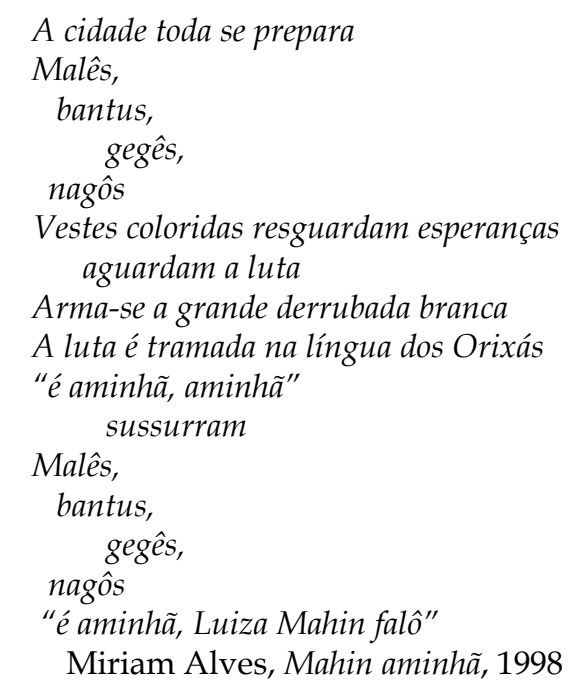

Ao finalizar a organização da Antologia de poesia afro-brasileira: 150 anos de consciência negra no Brasil (2011), constatei o aumento considerável da participação feminina na produção poética afro-brasileira nos últimos 20 anos. Essas vozes, quase ausentes do panorama da literatura afro-brasileira, não apenas tornam-se audíveis como adquirem grande força expressiva por apresentarem fragmentos da história do negro nas Américas a partir do ponto de vista da mulher. Grande parte dessa produção feminina se expressa por meio da poesia, sendo raras as que praticam as formas do romance, constituindo-se em exceção Conceição Evaristo e Ana Maria Gonçalves, cujas obras vêm consolidar a literatura afro como vertente fértil da literatura brasileira.

\footnotetext{
${ }^{1}$ Doutora e pós-doutora em língua e literatura francesa. Professora aposentada e colaboradora convidada do Programa de Pós-Graduação em Letras da Universidade Federal do Rio Grande do Sul (UFRGS), Porto Alegre, Brasil. Também é professora permanente do Mestrado em Memória Social e Bens Culturais do Centro Universitário La Salle (Unilasalle), Canoas, Brasil. E-mail: zilab@uol.com.br.
} 
No âmbito do presente artigo, nos interessa ressaltar a importância maior de Um defeito de cor (2010), de Ana Maria Gonçalves (1970), prêmio Casa de las Américas 2011, que inaugura o gênero roman-fleuve ${ }^{2}$ ou saga $^{3}$ no panorama da literatura negra ou afro-brasileira. Tambores de São Luís, de Josué Montello, e Viva o povo brasileiro, de João Ubaldo Ribeiro, constituíram-se em bem-sucedidas tentativas de dar conta da saga dos contingentes de africanos trazidos para as Américas na condição de escravos, abarcando vários séculos dessa incrível história feita de sofrimento e superação face às iniquidades do sistema escravagista. A obra de Ana Maria Gonçalves é, contudo, a primeira a narrar esses episódios do ponto de vista de quem mais sofreu nesse cruel processo: as mulheres, por serem mais fracas e vítimas constantes de violação. Essa obra é, portanto, para ser festejada por seu pioneirismo e pelas qualidades literárias que fazem com que o leitor não interrompa a leitura de suas 950 páginas, lendo-as de um só fôlego!

Cabe assinalar também outro fato interessante: no mesmo ano de 2010, outra importante escritora latino-americana, Isabel Allende, empreende audacioso relato, ao longo de 500 páginas, dos mais de 300 anos de história da escravidão na região do Caribe, abarcando o périplo da escrava Zarité, no Haiti, Cuba e Nova Orleans. Estava, portanto, na hora de termos acesso a essa história rasurada pela queima de documentos e distorcida por uma historiografia oficial a serviço das elites. Parte dessa história emerge agora, nas penas de Ana Maria Gonçalves e de Isabel Allende, revivificada pela enunciação feminina e pela astuciosa recuperação dos vestígios, dos rastros e das marcas conservadas na tradição oral e recuperada pelos testemunhos inscritos na memória coletiva de várias gerações.

Um defeito de cor se inicia justamente com um artifício literário bem conhecido (já utilizado por J. J. Rousseau e C. de Laclos, entre outros) que consiste em apresentar a obra ao leitor como tendo sido fruto de uma descoberta casual: a autora, ao visitar uma família na Ilha de Itaparica, para onde se mudara recentemente, encontra um conjunto de cartas - algumas já perdidas, outras danificadas e amarelecidas, porque o filho mais jovem da família as utilizava para desenhar - e as leva para ler. A narrativa que segue é o conjunto dessas cartas, escritas originalmente pela escrava alfabetizada Kehinde (que recebeu o nome católico de Luísa quando passou

\footnotetext{
${ }^{2}$ Romance-rio, que flui como um rio, "caracterizado pelo grande número de personagens e de ações que se sucedem e se imbricam” (Moisés, 1982, p. 461). São exemplos de romance-rio as obras de Tolstói (Guerra e Paz) e, no Brasil, de Érico Veríssimo (O tempo e o vento).

${ }^{3}$ Saga designa as narrativas épicas em prosa que, "mesclando fatos verídicos, folclóricos e imaginários, relatam a história de reis ou de famílias” (Moisés, 1982, p. 469).
} 
à condição de escrava) e dirigidas a seu filho desaparecido, supostamente o advogado e poeta Luís Gama, de quem ficou separada por longos anos. Essas cartas, reescritas pela autora, que completa suas lacunas, retraçam, a partir da vida dessa escrava, parcela importante da história dos negros no Brasil, desde o embarque nos navios negreiros, a chegada ao Brasil e a venda aos proprietários rurais, até a chegada às fazendas, os castigos, as fugas e o cotidiano na casa grande e nas senzalas, incluindo as separações entre mães e filhos e os estupros cometidos pelos senhores. Logo, é a partir de vestígios (traces), de cartas consideradas sem nenhum valor e semidestruídas, que a narrativa reconstitui importantes acontecimentos ocorridos na Bahia, como a revolta de escravos de origem muçulmana conhecida como a Revolta dos Malês (1835), que teve, na protagonista do romance, sua figura exponencial: Luísa Mahin, cujo nome africano era Kehinde.

Ao criar esse artifício narrativo, Ana Maria Gonçalves dá mais força à enunciação da protagonista, camuflando assim sua própria "autorida$\mathrm{de}^{\prime \prime}$, inerente à condição de autora. O contato do leitor se dá diretamente com essa voz, que começa a contar a história ainda antes da travessia do Atlântico, segue o relato em território brasileiro, continua narrando a segunda travessia (de volta para a África) e conclui com o relato de sua vida na África e do projeto de uma terceira e última travessia, de volta ao Brasil, na esperança de reencontro com o filho.

\section{A recuperação da voz das ancestrais femininas - nós da memória}

Como destacamos acima, a principal característica do fazer poético das autoras mulheres da literatura afro-brasileira atual é a de rastrear os "guardados da memória", como chama a poeta Ana Cruz, por meio dos traços, dos fragmentos deixados pela herança de suas antepassadas. A segunda característica dessa literatura é o que poderíamos chamar de "enraizamento dinâmico ou relacional", ou seja, a construção identitária baseada na procura das origens, que não negligencia os rastros deixados pela palavra materna e projeta-se no respeito à alteridade e no reconhecimento da diversidade da nação brasileira. Como terceira característica dessa poética negra no feminino, elencaríamos a tendência ao resgate da memória transatlântica. A obra de Ana Maria Gonçalves apresenta todos esses atributos: ao tentar resgatar as vozes e os saberes de sua mãe, avó e bisavó, a autora mergulha lá onde memória e mito se entrelaçam, dei- 
xando espaço para a imaginação redescobrir, completar e atualizar esses vestígios memoriais.

O romance se constrói num espaço intervalar entre memória e esquecimento cujas lacunas são preenchidas pelo resgate de imaginários de herança afro, atribuindo a si própria e à sua comunidade uma memória longa (G. Bouchard, 2009) ${ }^{4}$. As raízes dessa memória longa terão de ser buscadas muitas vezes do outro lado do Atlântico negro (cf. P. Gilroy, 2008), em tempos anteriores ao da travessia, preservadas na memória das mulheres que precederam a autora, em uma longa genealogia que remonta ao período inaugural do tráfico negreiro para as Américas. Ficam evidenciadas na narrativa: i) a memória histórica, que rememora fatos da história do negro no Brasil, deletados da historiografia oficial devido à condição que os descendentes de africanos ocupavam na sociedade brasileira; e ii) a memória familiar, que restaura ensinamentos da sabedoria contida na oralitura das gerações que a antecederam.

A palavra poética, melhor do que qualquer outra, deixa emergir o tempo do esquecimento, liberando o que ficou retido nos desvãos da história e nos descaminhos da memória. Não são as ideologias nem as mídias que desvelam o "espírito do tempo": somente as sensibilidades compartilhadas e as cumplicidades delimitam o espaço privilegiado onde os nós da memória poderão enfim ser desatados.

É oportuno ressaltar que o culto da ancestralidade é ambíguo, pois, ao adotar a memória da ancestralidade feminina, repudiam-se, de outro lado, os ancestrais masculinos, que, em muitos casos, eram os senhores brancos, responsáveis por atos de violência sexual contra as escravas. Lembrar ou esquecer essa "memória vergonhosa"? Em muitos casos a opção foi o pacto do silêncio que gerou, na argumentação de Bouchard, os "nós de memória", ou seja, a incapacidade de sublimar a violência e a criação de mitologias de substituição. Em Um defeito de cor, as agressões sexuais são narradas como estratégia de reapropriação do passado, "evacuando dos armários da memória, os esqueletos das origens" (Bouchard, 2009, p. 23). Ao invés de silenciar sobre as agressões, a narradora ancora sua identidade em uma memória longa que foi buscada do outro lado do Atlântico e nas agruras vividas na senzala, desfazendo os nós de memória pelo exercício salvador da escritura. Ao escrever as longas cartas dirigidas ao filho ausente, onde tudo é registrado, a narradora ganha forças para superar situações de extrema adversidade, rememorando os atos de bravura e heroísmo ocorridos durante as rebeliões de escravos, outro tabu de

\footnotetext{
${ }^{4}$ Também chamada por F. Braudel (1992) de memória de longa duração (longue durée).
} 
nossa historiografia, que tratou de construir o mito da docilidade do escravo africano e de sua aceitação da escravidão, diferentemente do índio, que não se deixou escravizar. Assim, articulando habilmente os jogos de memória longa, o romance traz à tona tanto os fatos de que os descendentes de ex-escravos podem se orgulhar - tais como a resistência à escravidão (formação dos quilombos, rebeliões, preservação da oralidade e dos rituais religiosos) - quanto aqueles que gostariam de esquecer, ou seja, os castigos cruéis e injustos, os abusos sexuais, as separações das famílias e, sobretudo, a privação dos direitos de cidadania.

Assim se exprime a narradora sobre seu constante embate contra o esquecimento:

Lembro-me de que, na época, escrevi tudo para não esquecer, pois não estava em condições de confiar na memória ou no senso de observação. E ainda hoje de nada me recordo, o que deve ser uma vingança da memória por eu não ter deixado que ela fizesse o trabalho sozinha (2010, p. 471).

\section{Reatualizando o conceito de vestígios ou rastros memoriais (traces)}

A noção de vestígio ou rastro pode ser definida como a presença de uma ausência. Nesse sentido, Ricoeur (2000) retoma a metáfora de Platão da marca de um anel em um bloco de cera quente: depois de retirado o anel fica ali impressa a representação presente de uma coisa ausente. Nesse sentido estabelece, na esteira de Marc Bloch, que haveria três tipos de rastros: i) o rastro escrito, que se tornou operação historiográfica; ii) o rastro psíquico (impressão ou afecção), correspondendo ao choque deixado por um acontecimento marcante ou trágico; e iii) o rastro cerebral (cortical), tratado pela neurociência (Bloch, 200, p. 32-33).

Um defeito de cor é tecido a partir da ativação de todos esses tipos de rastros. Primeiramente temos os rastros da oralidade trazidos pelos "migrantes nus" - para utilizarmos uma expressão de Édouard Glissant, em relação às migrações africanas para as Américas -, como as canções, os rituais religiosos e os provérbios, que se constituem em epígrafes de cada um dos dez capítulos em que se divide o romance. A epígrafe de abertura - "Quando você segue as pegadas dos mais velhos, aprende a caminhar como eles" - é bastante reveladora, já que "pegada" é sinônimo de rastro, vestígio, pois é a marca deixada na terra, constituindo-se em indício da passagem de seres humanos. 
Em segundo lugar, há os rastros escritos comprovados por uma extensa bibliografia e pesquisa em arquivos, fruto de árduo trabalho de levantamento de dados sobre a escravidão, realizado no Brasil e nos Estados Unidos, e que é arrolada ao final do romance. Todos os resíduos são considerados: o que restou nos arquivos escritos e orais são reativados pela sensibilidade e preenchidos pela imaginação criadora. A noção de vestígio está, pois, associada à presença de resíduos das práticas do passado naquilo que chamamos de presente. Assim, constrói-se a escritura como uma casa assombrada, uma casa habitada pelas intercorrências de recordações fragmentadas integradas ao tecido textual: rezas, mitos, citações, provérbios, cantigas de ninar, o ressoar dos tantãs e os rituais da cultura africana preservados na América malgrado as rigorosas proibições.

Mas talvez o grande ativador da memória sejam os rastros psíquicos deixados pelo impacto de violências cometidas, como os relatados à página 23, sobre o estupro e assassinato da mãe da narradora ainda em terras africanas, depois a morte da avó devido aos maus tratos durante a travessia no navio negreiro, e finalmente seu próprio estupro pelo sinhô José Carlos, de quem virá a engravidar de seu primeiro filho (p. 170-171). A morte desse filho e o nascimento do segundo - Luís -, também filho de um homem branco, deixam rastros indeléveis na memória da narradora; o maior de todos e motivador da longa busca registrada na escritura é o desaparecimento desse segundo filho, vendido como escravo pelo próprio pai em período em que a protagonista-narradora se afastara para realizar seu aprimoramento espiritual como uma vodúnsi (sacerdotisa do vodum) em terras do Maranhão.

Édouard Glissant retoma a metáfora do trace, valorizando-a. Afirma que "o pensamento dos traços/rastros/vestígios é aquele que se opõe hoje de maneira válida à falsa universalidade do pensamento de sistema" ${ }^{5}$ (1995, p. 15, tradução nossa). Utiliza essa imagem quando descreve o migrante nu (escravo) trazido à força da África e obrigado a aderir à cultura dos senhores, colocando a questão: o que vai se passar com esse migrante? "Ele recompõe por traços/fragmentos uma língua e artes que, poderíamos afirmar, são válidas para todos" (1995, p. 15, tradução nossa) $)^{6}$. O exemplo que o autor apresenta é o seguinte: a conservação por determinadas comunidades que chegaram ao Novo Mundo de tradições, cantos, lendas, cerimônias de enterro, festas, etc., foi muito difícil e se deu de forma fragmentária para o deportado africano, que chegou em situação

\footnotetext{
5 “La pensée de la trace est celle qui s'oppose aujourd'hui le plus valablement à la fausse universalité des pensées de système."

6 "Il recompose par traces une langue et des arts qu'on pourrait dire valable pour tous."
} 
muito precária e na condição de propriedade do senhor branco. Contudo, ele fez algo de imprevisível a partir unicamente do poder da memória: com base nos vestígios que lhe restaram, pôde (re)compor, de um lado, línguas crioulas sobre vestígios das línguas africanas e, de outro, formas de arte como o jazz, reconstituído nas Américas a partir de traces de ritmos africanos, e hoje considerado música de todos e não apenas da comunidade afro-americana (Glissant, 1995, p. 15).

Eurídice Figueiredo, em instigante artigo sobre Um defeito de cor, também aborda a questão dos vestígios, embora seu ponto principal de análise seja a "resiliência como resistência". A professora e pesquisadora assim reflete sobre a obra de Ana Maria Gonçalves:

Diante das histórias já contadas por escritores antes dela e que são retomadas numa trama intertextual, a autora coloca o leitor diante de um palimpsesto cujas diferentes camadas ele é levado a decifrar. O palimpsesto, como o bloco lógico de Freud, conserva os vestígios de escritas do passado, semi-apagadas, em diferentes traços que se embaralham (Figueiredo, 2011, p. 278).

\section{A busca da memória transatlântica - as três travessias}

As três travessias do Atlântico empreendidas pela protagonista-narradora nos obrigam a nos aproximar da bela metáfora criada por Paul Gilroy: o Atlântico negro. A incansável busca, primeiramente, da liberdade, da afirmação de si através da escrita e do filho desaparecido revelam um fascinante resgate memorial, reatualizando o que Gilroy chama de memórias transatlânticas, ou seja, aquelas que "fazem surgir culturas planetárias mais fluidas e menos fixas" (2008, p. 15). Segundo o autor de $O$ Atlântico negro, a aventura extranacional dos negros, que tem início com a diáspora africana, se caracteriza por "padrões de fluxo e mobilidade e pela criatividade intercultural" (cf. Gilroy, 2008, p. 15). Nesse sentido, memórias transatlânticas são aquelas que, ao cruzarem o meio fluido que é o mar, vão originar a "estrutura rizomórfica e fractal da formação transcultural e internacional a que chamo de Atlântico negro" (2008, p. 38).

\section{Primeira travessia}

Essa primeira travessia forçada e penosa realizada no tumbeiro e o trauma da chegada ao entreposto onde se realizavam as vendas de escravos provoca o início do processo de desterritorialização de Kehinde, que se vê forçada a assumir a língua portuguesa e a portar um novo nome, sendo portanto obrigada a despir-se de sua identidade africana - sem 
falar na imposição da religião católica. Na chegada à Ilha de Itaparica, na Bahia, inicia-se o lento processo de reterritorialização, em contato com outros escravos, que passam a constituir sua nova família, já que a avó e a irmã não sobrevivem à rudeza dos quase dois meses de viagem no tumbeiro.

Sua existência no Brasil será marcada por intensa mobilidade espacial, já que se desloca de Itaparica para Salvador e depois para o Maranhão, mudando várias vezes de domicílio, quando passa a escrava de aluguel e posteriormente quando consegue pagar por sua própria alforria. Na casa grande em Itaparica se alfabetiza junto com a filha dos senhores e, como escrava de aluguel em casa de ingleses, aprende a língua estrangeira dos patrões e também outros hábitos culinários como o de fazer cookies, o que vai garantir-lhe o sustento e o de seu primeiro filho em sua vida de liberta. Nessas travessias, espaciais e culturais, vão ocorrer os processos de mestiçagem e de transculturação, nos quais uma cultura, ao entrar em contato com a outra, gera produtos culturais novos e imprevisíveis no início.

Na medida em que o trans corresponde a ir além, ultrapassar, passar através, ele caracteriza uma forma de mobilidade que favorece a transação em termos de negociação e de renegociação e privilegia a conciliação de interesses aparentemente irreconciliáveis - um procedimento que exige concessões de um lado e de outro, trocas e aceitação recíprocas. No verbete "Transaction" (Dictionnaire de l'altérité et des relations interculturelles), Férreol define o conceito de transação como algo que "não se limita à negociação e à acomodação, mas leva, em muitos casos, a uma renovação do sentido por 'trânsito', 'mestiçagem' ou 'hibridação'" (Férreol, 2003, p. 339, tradução nossa).

A personagem-narradora do romance, que é poliglota, pois fala mais de uma língua africana, além do português e do inglês, transita, apesar de sua situação à margem na sociedade, entre diferentes etnias africanas em presença no Brasil, inclusive a de origem muçulmana, além do contato com os brancos, funcionando como uma espécie de passeur culturel, de atravessadora de culturas, construindo paulatinamente uma identidade dinâmica e relacional. "Na minha convivência com os brancos e mulatos, vi que nem todos eram maus, que existiam os de bom coração e até mesmo os que eram contra a escravatura, mas não haveria como separar uns dos outros" (p. 503).

Poderíamos afirmar que essas estratégias transculturais, que se encenam na grande diversidade cultural do Brasil, constroem um frágil equilíbrio relacional que vai sendo recriado como estratégia de sobrevivência da personagem. 


\section{Segunda travessia}

A narradora volta ao país natal, o antigo Daomé, hoje Benin, em 1847, à época do rei Guezo, quando a região é um grande centro de exportação de escravos para as Américas. A narrativa aqui se reveste de ambiguidade, na medida em que a personagem (que continua se dirigindo na narrativa ao filho desaparecido), enriquece com o tráfico de armas que pratica juntamente com o marido, John, um ex-escravo de origem inglesa. Ela insiste que não se envolve com o tráfico de escravos "embora muitos retornados fizessem isso sem remorso algum" (p. 771). Contudo as armas serviam para garantir o vantajoso comércio de escravos, dominado por um brasileiro, cognominado Chachá, figura de existência real, com quem a narradora mantém relações comerciais.

Esta talvez seja a parte menos interessante da obra, já que apresenta a narradora enriquecida, com sua família aumentando. Aqui o romance alonga-se desnecessariamente na tentativa de contar um pouco, como já o fizera Antonio Olinto, em A casa da água (1969), a vida dos retornados à África.

\section{Terceira travessia}

A travessia de volta ao Brasil, para reencontrar o filho finalmente localizado, é certamente uma travessia imaginária. A narradora já se encontra em idade avançada e cega, o que faz o leitor depreender que dificilmente essa viagem se realizará, embora o livro finalize, à página 947 , com a decisão de Luísa de rever o filho, uma vez que enfim obteve informações de seu paradeiro, após 30 anos de espera: "E talvez, num último gesto de misericórdia, qualquer um desses deuses dos homens me permita subir ao convés para respirar os ares do Brasil e te abençoar pela última vez".

A cegueira, como sabemos, é símbolo da "sabedoria dos velhos" e dos bardos itinerantes. Talvez, como nos ensinam Chevalier e Gheerbrant, a visão interior tenha por sanção a renúncia à visão das coisas exteriores: "O cego evoca a imagem daquele que vê outra coisa, com outros olhos, de um outro mundo: ele é percebido menos como um enfermo do que como um estrangeiro" (1973, p. 147, tradução nossa). A longa errância da personagem, sua intensa mobilidade entre espaços geográficos distintos e sua vida cheia de provações e de superações conferem-lhe, na velhice, sabedoria e iluminação espiritual, transformando-a de figura histórica em figura mítica.

O livro se fecha sob o signo do desejo da volta ao país natal - já que o Brasil se tornou para Kehinde/Luísa o país natal de adoção -, sob o signo do desejo do reencontro com o filho, cuja perda constitui-se na temática 
obsessional do romance, o que não deixa de ser paradoxal, uma vez que a narradora, além de mãe, teve um papel de grande destaque em rebeliões de resistência à escravidão, tornando-se uma heroína de seu tempo e figura exemplar para toda a comunidade negra e, em especial, para as mulheres negras, em sua luta pela igualdade racial.

Seu papel como heroína na Revolta dos Malês tem um destaque bem menos significativo no romance do que seu papel de mãe. Essa surpreendente valorização do papel da mãe em detrimento de sua atuação revolucionária coaduna-se com a perspectiva adotada por Carlo Ginzburg em seus livros, nos quais narrativa histórica e literária se atraem em um só campo magnético. Esse importante autor da história cultural privilegia sempre a particularidade: os fatos históricos são contados levando-se em consideração episódios vividos por um indivíduo, que se torna exemplar para todo o contexto sócio-histórico que o historiador pretende focalizar. No romance de Ana Maria Gonçalves, da mesma forma, é a partir de um caso singular - a mãe, escrava liberta, apartada do filho - que a saga da escravidão e os episódios das rebeliões de escravos se desdobram diante do leitor. É desde uma experiência humana, do olhar de uma escrava e não de um vencedor, que a escritora mineira traz à tona o complexo $\mathrm{e}$ multiforme painel do século XIX no Brasil, onde o regime escravista se manteve até 1888 .

\section{Um defeito de cor}

Eurídice Figueiredo, no artigo citado anteriormente, recorda que o título do livro de Ana Maria Gonçalves foi inspirado por uma frase do poeta Luís Gama, que retomamos aqui:

Em nós, até a cor é um defeito. Um imperdoável mal de nascença, o estigma de um crime. Mas nossos críticos se esquecem que esta cor é a origem da riqueza de milhares de ladrões que nos insultam; que essa cor convencional da escravidão, tão semelhante à da terra, abriga sob sua superfície escura, vulcões onde arde o fogo sagrado da liberdade (Gama, 2008 apud Figueiredo, 2011, p. 277)

Na obra, a autora, de modo muito sutil, deixa de mencionar o nome do poeta, suposto filho da protagonista, embora forneça todas as pistas para que, em uma leitura acurada, se decifre que a protagonista escreve uma longa carta dirigida ao filho que foi ilegalmente vendido como escravo - pois nasceu livre, já que a mãe Kehinde-Luísa era alforriada à época do nascimento de Luís - pelo próprio pai, fidalgo arruinado, para pagar dívidas de jogo. 
Foi possível confirmar nossa hipótese de leitura: a saga de Ana Maria Gonçalves pode ser analisada com base na estética dos vestígios, que se desdobra em diferentes estratégias narrativas:

- No prólogo, intitulado "Serendipidades" - termo que remete à situação em que, procurando-se determinada coisa, encontra-se outra sobre a qual já havia alguma expectativa -, inicia-se o jogo narrativo que implica a estratégia da autora de apresentar-se apenas como a pessoa que elaborou a transcrição de um texto encontrado em condição fragmentária, cheio de lacunas, rasuras e omissões. A precariedade dos textos exige um paciente trabalho de reescritura visando à composição do palimpsesto onde rastros de outras escrituras se entrecruzam.

- $\quad$ No topos da busca do filho, seguem-se indícios de seus possíveis deslocamentos, tendo sido vendido e revendido várias vezes. À página 634, a narradora intitula de "O rastro" um subcapítulo em que informa que, após o desaparecimento do filho, só lhe resta seguir algumas pistas, "um fio de história que deveria ter começo e fim".

- $\quad$ Ao longo da narrativa, que se constrói com base em dados duvidosos: i) sobre as revoltas dos escravos de origem muçulmana sobre as quais há escassos registros históricos; ii) sobre a própria personagem Luísa Mahin, cuja existência é em muitos textos questionada, construindo-se nos interstícios do mito e da realidade, com base em vestígios de narrativas orais; iii) sobre a religiosidade afrobrasileira e a preservação dos rituais trazidos da África para o Novo Mundo cujas práticas, como se sabe, eram proibidas por serem consideradas transgressoras e sacrílegas.

Se retomarmos a reflexão sempre fertilizadora de Édouard Glissant, podemos afirmar que a enunciação feminina no romance, baseada em traces, constitui-se, apesar de sua aparente fragilidade, no que o autor chama de "pensée de la trace" (pensamento dos vestígios, dos rastros), que se instala em oposição a "pensée de système", ou seja, ao racionalismo e ao pragmatismo que caracteriza a tradição das culturas ocidentais. O pensamento dos vestígios, desenvolvido levando em conta as sensibilidades, conduz a uma visão histórica dos fatos ocorridos, no período escravista, muito mais complexa.

A historiadora da cultura Sandra Jatahy Pesavento argumenta sobre a importância para a história cultural de apostar em conceitos como imaginário e sensibilidade: 
Assim, a sensibilidade assume um caráter relacional, como percepção do mundo, entre aquilo que é dado a ver e o que pode ser visto de forma indireta. Sentir é uma forma de conhecer - emoções e sentimentos - o que não elimina processos cognitivos de outra ordem, próximo ao mundo da ciência (Pesavento, 2008, p. 25).

Daí vem o título do artigo: "Pensar com o sentimento, sentir com a mente". Um defeito de cor se esforça por mesclar constantemente o racional, o sensível, o imaginário coletivo e o simbólico para penetrar no emaranhado multicultural e multirracial que conformava o cenário do Brasil do século XIX, tentando perceber a complexidade da memória social desse período.

Em instigante artigo, intitulado "O rastro e a cicatriz: metáforas da memória", Jeanne-Marie Gagnebin (2009) assinala que o trauma gera a ferida que posteriormente se transforma em cicatriz. A escrita sobre essas cicatrizes é uma escrita que se pretende reveladora dos indícios por trás das cicatrizes deixadas pelos traumas sofridos pela população escrava. Assim, a escrita também se transforma em rastro que, segundo a autora, é fruto do acaso, denunciando a presença ausente de que falávamos no início do presente artigo. Narrar o vivido em tempos de escravidão consiste em ato de subversão, já que as elites empenhavam-se em aniquilar os rastros, queimando documentos e assassinando testemunhas oculares. Citando Walter Benjamin, Gagnebin conclui que, "ao juntar os rastros-restos que sobram da vida e da história oficiais, poetas, artistas e mesmo historiadores não efetuam somente um ritual de protesto. Também cumprem a tarefa silenciosa, anônima, mas imprescindível, do narrador autêntico e, mesmo hoje, ainda possível: a tarefa, o trabalho de apokatastasis, essa reunião paciente e completa de todas as almas do Paraíso, mesmo das mais humildes e rejeitadas, segundo a doutrina teológica" (2009, p. 118).

A literatura que assume a tarefa de recolher os restos e decifrar os rastros, como a de Ana Maria Gonçalves, insurge-se contra a tendência dos regimes autoritários de apagar os vestígios dos crimes por eles cometidos contra a humanidade.

\section{Referências}

ALLENDE, Isabel (2010). A ilha sob o mar. Rio de Janeiro: Bertrand Brasil. BERND, Zilá (org.) (2010). Dicionário das mobilidades culturais: percursos americanos. Porto Alegre: Literalis.

(2011). "Vestígios memoriais: fecundando as literaturas das Américas". Conexão Letras, v. 6, n. 6, p. 9-16. 
(org.) (2011). Antologia de poesia afro-brasileira: 150 anos de consciência negra no Brasil. Belo Horizonte: Mazza.

BOUCHARD, Gérard (2009). “Jogos e nós de memória: a invenção da memória longa nas nações do novo mundo". Trad. Z. Bernd. In: LOPES, Cícero Galeno et al. (Orgs.). Memória e cultura: perspectivas transdisciplinares. Canoas: Salles/ Unilasalle.

BRAUDEL, Fernand (1992). Escritos sobre a história. 2. ed. São Paulo: Perspectiva. CHEVALIER, Jean ; GEERBRANT, Alain (1973). Dictionnaire des symboles. v. 1. Paris: Seghers.

FERREOL, Gilles ; JUCQUOIS, Guy (2003). “Transaction”. In : Dictionnaire de l'altérité et des relations interculturelles. Paris: Armand Colin.

FIGUEIREDO, Eurídice (2011). "Resiliência como resistência na escrita de Ana Maria Gonçalves". In: BOLAÑOS, Aimée; ROJAS, Lady B. (Orgs.). Voces negras de las Américas: diálogos contemporâneos / Vozes negras das Américas: diálogos contemporâneos. Rio Grande: Editora da FURG.

GAGNEBIN, Jeanne-Marie (2002). "O rastro e a cicatriz: metáforas da memória". Pro-posições, v. 13, n. 3 (39), p. 125-133. (Retomado em Lembrar escrever esquecer. 2. ed. São Paulo: Editora 34.)5

GAMA, Luís (2011). “Luís Gama” (on-line). Disponível em: <http:/ / pt.wikipedia. org/wiki/Lu\%C3\%ADs_Gama>. Acesso em: 24 set 2011.

GILROY, Paul (2008). O Atlântico negro. Rio de Janeiro: Candido Mendes; São Paulo: Editora 34

GINZBURG, Carlo (2009). O fio e os rastros. São Paulo: Companhia das Letras. (1989). "Sinais: raízes de um paradigma indiciário". In: Mitos, emblemas, sinais: morfologia e história. 2. ed. Trad. Federico Carotti. São Paulo: Companhia das Letras.

GLISSANT, Édouard (1995). Introduction à une poétique du divers. Montreal: Presses de l'Université de Montreal.

GONÇALVES, Ana Maria (2010). Um defeito de cor. Rio de Janeiro: Record.

MOISĚS, Massaud (1982). Dicionário de termos literários. 3. ed. São Paulo: Cultrix.

NASSIF, Luís (2011). "Luísa Mahin e sua saga". Portal Luís Nassif. Disponível em: <http://blogln.ning.com/profiles/blogs/luisa-mahin-e-sua-saga>. Acesso em: 25 set 2011.

PESAVENTO, Sandra (2007). "Sensibilidades: escrita e leitura da alma". In: LANGUE, Frédérique (Org.). Sensibilidades na história: memórias singulares e identidades sociais. Porto Alegre: Editora da UFRGS.

(2008). "Pensar com o sentimento, sentir com a mente". In: RAMOS, Alcides Freire; MATOS, Maria Izilda Santos de; PATRIOTA, Rosangela (Orgs.). Olhares sobre a história. São Paulo: Hucitec; Editora da PUC-GO.

RICOEUR, Paul (2007). A memória, a história, o esquecimento. Trad. Alain François et al. Campinas: Editora da Unicamp.

TRACE / desconstrução (verbete). In: Wikipedia. Disponível em: <www.wikipedia. com>.

TRACES (1963). Nouvelle Revue Française, v. 11, n. 129, p. 472-480.

WALTER, Roland (2009). Afro-América: diálogos literários na diáspora negra das Américas. Recife: Coleção Letras, PPG/Letras UFPE. 
Recebido em dezembro de 2011.

Aprovado em março de 2012.

\section{resumolabstract}

Em busca dos rastros perdidos da memória ancestral: um estudo de Um defeito de cor, de Ana Maria Gonçalves

Zilá Bernd

O artigo se detém em uma reflexão teórica sobre o conceito de vestígios (traces), evocando os principais autores que o definiram, como P. Ricoeur, C. Ginzburg, J.M. Gagnebin, E. Glissant e S. J. Pesavento, entre outros, e introduzindo variantes terminológicas como "rastros", "restos", "resíduos", "marcas" etc.. Leva-se em conta a importância desse conceito para repensar o trabalho da memória em textos literários contemporâneos e, em particular, no romance Um defeito de cor, de Ana Maria Gonçalves (Record, 2010), que se constitui em valioso exemplo de resgate da memória coletiva afro-brasileira, por meio de vestígios.

Palavras-chave: vestígios memoriais, rastros (traces), memórias transatlânticas, ancestralidade, memória coletiva afro-brasileira, Ana Maria Gonçalves

Looking for lost traces of the ancestral memory: a study of Um defeito de cor, by Ana Maria Gonçalves

Zilá Bernd

The article provides a theoretical reflection upon the concept of traces, evoking the main authors who have defined it, such as P. Ricoeur, C. Ginzburg, J.-M. Gagnebin, E. Glissant and S. J. Pesavento, among others, and introducing terminological variants such as vestiges, ruins, residues, marks etc. We consider the importance of this concept in order to rethink the memory work in contemporary literary texts, especially in Ana Maria Gonçalves' novel Um defeito de cor (Record, 2010), which is an outstanding example of the recovery of African-Brazilian collective memory from traces.

Keywords: memory traces, transatlantic memories, ancestries, African-Brazilian collective memory, Ana Maria Gonçalves 